\title{
Salient Studies of Signed Language Interpreting in the Context of Community Interpreting Scholarship
}

\author{
Melanie Metzger \\ Gallaudet University
}

During the past four decades, signed language interpreting (SLI) scholars have created a growing body of research. This work covers a broad range of topics, from a psycholinguistic perspective to a sociolinguistic one, from analyses of the cognitive processes in which signed language interpreters engage, to analyses of the management and participation framework of interpreted events, from linguistically-oriented studies to studies focused on aspects of the environment in particular settings or various applications of the interpreting process that impact on the flow and outcome of the interpreted event, be it consecutive or simultaneous work, in-person or via technology. Yet these contributions to our understanding of SLI neither occur in a vacuum, nor do they reflect issues limited to SL interpreters. This paper examines seminal studies in SLI research, and contextualizes them within the larger framework of community interpreting research.

\section{Introduction}

The field of interpretation can be considered from numerous perspectives. Conference interpreting and community interpreting are often considered as separate from one another, and further still, signed language interpretation (SLI) is sometimes identified as a separate category within the field as a whole. In fact, dissecting interpretation into taxonomies (see Pöchhacker 2004) related to task, language pair or modality, paradigm, or research methodology, is quite useful and provides the necessary foundation from which numerous significant activities can spring such as teaching or studying the history of the field, or from which empirical studies can be contextualized within the tapestry of studies that has been woven together since the first empirical examinations of interpreting were conducted in the 1950's. Nevertheless, any given taxonomy necessarily reflects a particular point of view. For example, where conference and community interpreting might diverge with regard to discourse genre, they might also converge with regard to research methodology if one were to focus on quantitative studies focusing on survey or experimental methods. For this reason, repeated examination of a field, with a variety of points of view, is quite useful to practitioners, educators, students, and scholars.

This paper will focus on an area sometimes rightfully reserved to its own category within the field: signed language interpretation. Historically, signed and spoken language interpretation have been compared in a variety of ways. According to Roberts (1987), spoken language interpreters 
throughout recent history have worked in conference situations and other high-profile settings, whereas SLI has predominated in community, dialogic situations. Roberts suggests also that spoken language interpreters have been treated with some prestige, perhaps related to the settings in which they work, whereas SL interpreters have often had to deal with linguistic prejudices or misunderstandings regarding the status of signed languages as fully fledged linguistic systems.

Whether or not these two factors remain current, one clear distinction between the work of SL interpreters and spoken language interpreters is the difference in mode. That is, where most spoken language interpreters work primarily between two spoken languages, most SL interpreters work between one spoken language and one signed language. This modality difference has implications on practice. For example, SL interpreters working in the consecutive mode must use their hands and eyes linguistically, which affects the ability to engage in note-taking practices that might be employed by spoken language interpreters. Conversely, spoken language interpreters face the issue of simultaneous auditory input and output.

A final point to be made when contrasting spoken and SL interpretation is that where one might expect, in spoken language interpreting contexts, that the primary participants do not know each other's language, this may not be the case for SL interpreters. Deaf consumers of SLI may often be bilingual in both languages used in an interpreted event, but the spoken language in face-to-face encounters is not accessible. Thus, SL interpreters might face circumstances in which one of the primary participants is actually bilingual, raising questions regarding language contact and notions of free versus literal interpretation that have long been debated within the field of translation and interpretation (Metzger 1999).

But despite these distinctions between spoken and SLI, the bulk of the work performed by interpreters remains quite similar. The ultimate task of telling one person what another has said in a different language, and all that this implies in terms of the interpreter's ability to make sense of source utterances, process them and reformulate them into a second language is consistent, even without regard for language pair or modality. Moreover, both spoken and SL interpreters work in countries around the globe, and in settings that include both community and conference interpreting.

This paper will diachronically compare empirical, data-based studies of SLI, with an eye on issues critical within the SLI profession, and contextualize them within the field at large. To accomplish this task, the underlying focus of the paper will be to first examine these SLI studies by decade, then to further discriminate among these studies on the basis of topic (keeping in mind that any one study might reflect more than one topic of inquiry, such as medical interpreting and participation framework) and methodology (e.g., quantitative or qualitative, experimental or naturalistic). Two other categories that became salient when examining these studies, and that will be included here, are the countries represented by these SLI studies and the paradigm reflected by the studies, based on the paradigmatic categories described in Pöchhacker (2004). 
The total number of studies to be examined is 97 . These begin with the first identified empirical studies of SLI, which began in the U.S. in the 1970s, nearly twenty years after the first modern studies of spoken language interpretation were conducted. The 97 studies represented here are culled primarily from two sources: the International Bibliography of Sign Language database, accessible at www.sign-lang.uni-hamburg.de, and the Journal of Interpretation, published by the Registry of Interpreters for the Deaf, the professional association of SL interpreters in the U.S. The studies examined in this paper cover four decades, the 1970s, 1980s, 1990s, and 2000s, and the description of these studies, by decade, will be followed by a summary and conclusion. It is worth emphasizing three points about the studies included in this examination below. First, only those studies that appear in the database or journal are included, and of those, only the studies that could be obtained in hard copy for analysis ${ }^{1}$. Second, only those studies that are clearly empirical and data-based are included in this examination. Finally, the purpose of this examination is to begin to develop a sense of studies within the field of SLI and the analysis does not include a critique of the quality of the studies examined. A qualitative analysis of this type is beyond the scope of this paper.

\section{Empirical studies of SLI: 1970s}

Early empirical examination of SLI began during the 1970s with the earliest data-based studies located thus far published in 1974, in a special issue of the Journal of Rehabilitation for the Deaf.

\subsection{Topics of the $1970 \mathrm{~s}$}

Of the seven topics that received focus during the 1970s, the most significant topic of investigation during this decade is that of interpreter effectiveness and or characteristics. This topic was relevant for all ten of the studies identified during this time period, regardless of other topics addressed additionally (see table 1 below). In the earliest studies conducted on this issue, Brasel et.al. (1974) focused their attention on a survey of interpreters, attempting to determine what practitioners themselves viewed as component skills of interpreting while Schein (1974) combined psychological testing instruments with analyses of interpretations of recorded source texts in an effort to link personality characteristics with interpreting skill.

Another topic reflected in these early studies is the examination of source and target texts. For example, Schein's (1974) study compared the source and target texts of interpreters to establish the link between personality characteristics and ability. Over three-quarters of the studies compared source and target, within the context of the effectiveness of the interpretation, using a variety of means for making the comparison, including inter- 
pretations followed by multiple choice tests for the "audience" (Fleischer 1975; Murphy \& Fleischer 1976; Norwood 1976).

One topic that is typically of great interest to spoken language interpreters related to the cognitive processes involved in interpretation. This topic is addressed in just under one fourth of these early SLI studies. Although the percentage is small, clearly, the topic is of interest. Of the studies that reflect an interest in cognitive processing, one focuses on the effects of fatigue on the competence of interpreters, finding that interpreters work best in 20-30 minute stretches (Babbini 1976). Although this is a relatively small scale study, the 20-30 minute time frame has become common practice for interpreters working in teams, and this practice can be traced to this early study (Roy, personal communication, 2005).

During the 1970s in the US, legislation had been, or was being passed, that supported the notion of providing interpreters between deaf and hearing individuals. For example, in 1975 federal legislation required that deaf children be provided access to education, which often meant that deaf students would join hearing students in hearing, public schools, with an interpreter (rather than attend classes conducted visually in American Sign Language (ASL) at a school for deaf children). Within the field of SLI, legislation such as this has had an impact on the settings in which community interpreters found themselves, working not only in university contexts, but interpreting now from kindergarten through high school pre-college classrooms. The significance of educational interpreting can be seen in the breakdown of topics for the $1970 \mathrm{~s}$, as nearly three-quarters of the studies in this decade pull data from post-secondary interpreting situations (see Table 1 below).

In addition to the educational setting, studies in this decade also address conference interpreting $(10 \%)$ and interpreting in the media $(20 \%)$, the latter in a comparison of interpreted versus captioned television newscasts (Norwood 1976).

Table 1: Empirical studies of SLI: 1970s topics.

\begin{tabular}{|c|c|c|c|}
\hline $\mathbf{N}=\mathbf{1 0}$ & $\#$ & $\mathbf{\%}$ \\
\hline \multirow{4}{*}{ Topic } & $\begin{array}{c}\text { Interpreter } \\
\text { Effectiveness/Characteristics }\end{array}$ & 10 & $100 \%^{2}$ \\
\cline { 2 - 4 } & Source-to-Target Comparison & 8 & $80 \%$ \\
\cline { 2 - 4 } & Cognitive Processing & 2 & $20 \%$ \\
\cline { 2 - 4 } & $\begin{array}{c}\text { Language contact: } \\
\text { free vs literal }\end{array}$ & 3 & $30 \%$ \\
\cline { 2 - 4 } & Educational Interpreting & 7 & $70 \%$ \\
\cline { 2 - 4 } & Conference Interpreting & 1 & $10 \%$ \\
\cline { 2 - 4 } & Television Newscasts & 2 & $20 \%$ \\
\hline
\end{tabular}


This summary of studies during the 1970s as seen in Table 1 shows that seven different topics received attention during this time period, three of them related to specific community settings in which SL interpreters work.

\subsection{Methodologies of the 1970s}

As can be seen in Table 2 below, all studies examined from this decade are quantitative in methodology.

Table 2: Empirical studies of SLI: 1970s methodology. ${ }^{3}$

\begin{tabular}{|c|c|c|c|}
\hline $\mathbf{N}=\mathbf{1 0}$ & $\#$ & $\mathbf{\%}$ \\
\hline \multirow{4}{*}{ Method } & Quantitative & 10 & $100 \%$ \\
\cline { 2 - 4 } & Qualitative & - & - \\
\cline { 2 - 4 } & Mixed method & - & - \\
\cline { 2 - 4 } & Survey & 2 & $20 \%$ \\
\cline { 2 - 4 } & Experimental & 8 & $80 \%$ \\
\cline { 2 - 4 } & Naturalistic & 1 & $10 \%$ \\
\hline
\end{tabular}

Of these quantitative studies, $80 \%$ are experimental in design. Less than one fourth of the studies are based on survey data, and only $10 \%$, represent naturalistic data. The naturalistic data was used in one study that focused on the extent to which deaf college students attended to an interpreter during an interpreted course activity. For this study, evidence of "attention" was based on eye gaze from a deaf student to the signed language interpreter. During live observation, and for a period of five minutes, eye gaze was observed. Findings indicated that students were influenced to some extent by the presence of the researcher, as eye gaze for an initial observation session was directed toward the observer quite frequently. This study is worth mentioning for at least three reasons. Firstly, a similar study of attention to spoken language interpreters is not possible (at least, not using a similar design), since the eye and the ear function so differently. One cannot measure the extent to which a primary participant "listens" to an interpretation. Secondly, measurement of eye gaze is a useful tool for examining attention, but it is worth noting that eye gaze alone does not guarantee attention. Thirdly, this study is notable as one that used naturalistic data at a time when experimental data was much more common. 


\subsection{Countries represented during the $1970 \mathrm{~s}$}

Of the studies located from the 1970 s, $100 \%$ represent studies by and about signed language interpreters in the US (see Table 3)

Table 3: Empirical studies of SLI: 1970s countries represented.

\begin{tabular}{|c|c|c|c|}
\hline \multicolumn{2}{|c|}{$\mathbf{N}=\mathbf{1 0}$} & $\#$ & $\mathbf{\%}$ \\
\hline Countries & US & 10 & $100 \%$ \\
\hline
\end{tabular}

As will be seen in later sections of this paper, the number of countries represented increases over time.

\subsection{Paradigms represented in the $1970 \mathrm{~s}$}

Interpreting scholars recognize that empirical studies of interpretation reflect the basic assumptions and theories of a given time (Moser-Mercer 1994; Shlesinger 1995). Pöchhacker (2004) describes five approaches to research reflecting paradigms within interpreting scholarship, covering roughly the same span of time as the studies examined in this paper. These five paradigms are applied to the studies in this paper, in order to contextualize the SLI studies within the larger context of interpreting scholarship. ${ }^{4}$

The first paradigm is the Interpretive Theory of Translation most notably associated with Seleskovitch and Lederer (see Seleskovitch 1975; Lederer 1981). The emphasis in this 'théorie du sens' is on the transfer of meaning from one language to another via a process of 'déverbalisation', stripping the source message of its linguistic packaging and transferring it in content and intention into the formal linguistic constraints of the target language. The focus here is exclusively on conference interpreting, both simultaneous and consecutive. The 97 studies represented here do not largely represent this paradigm, due to the heavily reflective nature and conference interpreting emphasis of this tradition, ${ }^{5}$ but SL interpreters in the US have drawn greatly from this paradigm, and Seleskovitch herself has presented keynote addresses at national SLI conventions as well as published in SLI journals (Seleskovitch 1992).

Neurolinguistics offered one of the first paradigms for analyzing interpretation drawing on both theories and methods that extended beyond translation itself (Pöchhacker 2004: 81). Fabbro et al. (1990) and Fabbro and Gran (1994) are most notably associated with this paradigm, which also focuses heavily on the question of cognitive processing, but which is influenced by the frameworks of neurophysiology and neuropsychology. The most common methodology associated with this paradigm is experimental.

Cognitive processing is the paradigm that reacted most directly to the interpretive theoretical approach, as conference interpreters became more interested in applying more rigorous, scientific methods to the study of interpreta- 
tion (cf. Gile 1990). The Cognitive Processing paradigm described in Pöchhacker (2004) is associated initially with the work of Gerver (1976) and founded in the framework of cognitive psychology. Research methods most commonly associated with this tradition include fieldwork, as well as experimental and survey-based strategies. The focus is typically on conference interpreting, including both simultaneous and consecutive. Numerous models of these cognitive processes - taking their inspiration especially from Gerver (1976) and Gile's (1995) 'effort model' - have also been developed by SLI theorists (see e.g. Gish 1986 and Cokely 1985), but theoretical models, unless based on empirical data, are beyond the scope of this paper.

By the 1980s, interpreting scholars expanded their interests beyond cognitive processes and began to explore the texts themselves. Analyses of target texts, involving both text linguistics and discourse studies, find a framework in the 'skopos' or Target-Text-Oriented Translational Theoretical approach, most notably associated with Shlesinger (1989) and Pöchhacker (1994). This paradigm, grounded in translation and discourse studies, relies methodologically on fieldwork and survey-based research designs, focusing on both conference and dialogue interpreting.

Finally, grounded in sociology and sociolinguistics, the 1980s saw the emergence of the Dialogic Discourse-based Interaction paradigm, associated with Wadensjö $(1992,1998)$ and Roy $(1989,2000)$. The primary methodology within this paradigm is fieldwork, and the focus of studies within this tradition are largely dialogic and, hence, quite grounded in community interpreting. Roy herself is an SLI scholar, and her seminal 1989 study of turn-taking exchanges in an interpreted event has contributed greatly to later studies of both signed and spoken language interpretation that emphasize discourse-based interaction over the information processing emphasis of earlier studies of interpretation.

Table 4: Empirical studies of SLI: 1970s paradigm.

\begin{tabular}{|c|c|c|c|}
\hline $\mathbf{N}=\mathbf{1 0}$ & $\#$ & $\%$ \\
\hline \multirow{4}{*}{ Paradigm } & $\begin{array}{c}\text { Interpretive Theory of } \\
\text { Translation }\end{array}$ & - & - \\
\cline { 2 - 4 } & Neurolinguistic & - & - \\
\cline { 2 - 4 } & Cognitive Processing & 2 & $20 \%$ \\
\cline { 2 - 4 } & $\begin{array}{c}\text { Target-Text oriented } \\
\text { translational-theoretical approach }\end{array}$ & 8 & $80 \%$ \\
\cline { 2 - 4 } & Discourse-based Interaction & - & - \\
\hline
\end{tabular}

Only two paradigms are reflected in the 1970s studies under examination here. Over three-quarters of the studies seem to fit Pöchhacker's description of the text-oriented approach, as they focus on text production and/or mediation. Just under one fourth of the studies in this decade fit the Cognitive Processing paradigm. The studies themselves do not self-identify paradig- 
matic grounding, nor do they necessarily provide an in-depth description of the theoretical framework from which the study emerges. Despite the fact that the Target-Text Oriented paradigm was not officially 'born' in spoken language interpreting studies in Europe until the late 1980s or early 1990s, these early SLI studies conform to the methodological strategies (surveys or fieldwork) and the text production focus described as typical of this tradition (by Pöchhacker 2004). These works do remain seminal, however, as these earlier SLI studies do not go into such relevant issues as translational norms (Toury 1995) or skopos theory (Vermeer 1989). Nevertheless, they clearly reflect an early interest in the contextualized effectiveness of target texts and the communicative needs of the target audience in both monologic and dialogic interpreted events, thus working along the lines of, for example, Nida (1964) or Kirchoff (1976) in translation studies. Clearly the early focus of researchers in SL community interpreting was a functionalist approach rather than solely an information-processing one, with a heavy reliance on quantitative, experimental methods, rather than on fieldwork.

\subsection{Summary of the $1970 \mathrm{~s}$}

The studies from the 1970s represent seven different topics of examination and one predominant methodological approach (quantitative). Further, only one country is represented by these studies, the US. The cognitive processing and target-text oriented paradigms are the two reflected in the studies of this decade. In addition, one seminal study, though small, about the impact of fatigue on SL interpreters, suggesting that 20-30 minutes is the length of time SL interpreters can work best without fatigue impacting their performance, has had a huge impact on SLI practice in the US. Finally, early studies within the 1970s take a more functionalist approach combined with an experimental design, and place less emphasis on cognitive processing than might be seen in studies of spoken language interpretation during a similar time frame.

\section{Empirical studies of SLI: $1980 \mathrm{~s}$}

Examination of those empirical signed language interpreting studies located from the 1980s reveals some changes from the decade preceding. A total of twenty-four of the 97 studies occur during the 1980s. Of these, a larger number of topics are represented, as is a greater selection of methodology and paradigms from which to ground the research. Most of the studies examined still represent the US, though this will continue to change over the subsequent two decades. 


\subsection{Topics of the $1980 \mathrm{~s}$}

In addition to the seven topics represented during the 1970s, two topics appear during the 1980s : working conditions and occupational safety, and the interpreter's role within community interpreting.

Table 5: Empirical studies of SLI: 1980s topics.

\begin{tabular}{|c|c|c|c|}
\hline $\mathbf{N}=\mathbf{2 4}$ & $\#$ & $\mathbf{\%}$ \\
\hline \multirow{4}{*}{ Topic } & $\begin{array}{c}\text { Interpreter } \\
\text { Effectiveness/Characteristics }\end{array}$ & 8 & $33 \%$ \\
\cline { 2 - 4 } & Source-to-Target Comparison & 6 & $25 \%$ \\
\cline { 2 - 4 } & Cognitive Processing & 4 & $17 \%$ \\
\cline { 2 - 4 } & $\begin{array}{c}\text { Language contact: } \\
\text { free vs literal }\end{array}$ & 5 & $21 \%$ \\
\cline { 2 - 4 } & $\begin{array}{c}\text { Interpreter Education and/or } \\
\text { Assessment }\end{array}$ & 2 & $8 \%$ \\
\cline { 2 - 4 } & $\begin{array}{c}\text { Working Conditions/ } \\
\text { Occupational Safety }\end{array}$ & 3 & $13 \%$ \\
\cline { 2 - 4 } & Educational Settings & 6 & $25 \%$ \\
\cline { 2 - 4 } & Conference Interpreting & 6 & $25 \%$ \\
\cline { 2 - 4 } & Role/Code of Ethics & 2 & $8 \%$ \\
\hline
\end{tabular}

Like the $1970 \mathrm{~s}$, the topic receiving the most attention in the 1980 s relates to interpreter effectiveness and characteristics. However, during the 1980s there is a greater diversity of topics within the studies, so whereas this topic constituted $100 \%$ of the studies in the 1970 s, it constitutes only $33 \%$ of the studies from the 1980s. Like the 1970s, the next two topics receiving the most attention include source-to-target comparisons and educational interpreting. However, studies from the 1980s also reflect a similar level of interest in a third topic, conference interpreting. Each of these three topics represents about one fourth of the total number of studies located from this decade. This diverges from the history of scholarship within spoken language interpreting, where conference interpreting was the first area to receive attention, with community interpreting receiving more attention in later years. SLI studies began in the 1970s with an emphasis on interactive, community settings, primarily in post-secondary institutions. During the 1980 s, examination of interpreters in classrooms extends to include kindergarten through high school (Finnegan 1986; Gustason 1985).

As in the 1970s, the topic receiving the next level of attention is language contact in the issue of 'free' versus 'literal' interpreting. In this decade, this topic reflects $21 \%$ of the 24 studies, and is followed closely by cognitive processing at $17 \%$. Notably, one study from within the former category, Winston (1989) combines the topic of language contact with a 
source-to-target comparison in her examination of a literal interpretation (commonly referred to as "transliteration" within the SLI field in the US). Her study represents a seminal work for two reasons. First, this is the first study to examine the discourse features of a literal interpretation, and therefore, to identify linguistic evidence of language contact within the target text. Second, this study was selected by the professional association for SL interpreters in the US as the sample representing the standard for professional certification, when being tested for literal interpretation ("transliteration"). Thus, this study is well-known and well-cited in the US with regard to literal interpretation.

Similarly, within the topic of cognitive processing, another seminal work appears during the 1980s. Cokely (1985) examines six conference interpreters with a focus on both temporal and linguistic analyses of their interpretations between American Sign Language and spoken English. In this study, Cokely combines the examination of processing issues (based on analyses of lag time, for example, and the impact of this on the target text) with attention to mediation between individuals and cultures as well as the two languages, resulting in a sociolinguistic model of the interpreting process.

Working conditions and occupational safety become evident in the studies located from the 1980s (Greenhaw 1985; LaVor 1985; Watson 1987), reflecting $13 \%$ of the 24 studies. These 1980 s studies are all surveybased.

The remaining two topics each constitute just $8 \%$ of the 24 studies. Interpreter education and/or assessment during this decade includes studies of interpreter education programs (Gustason 1985) as well as a continued interest in identifying personality types related to the academic preparation or skills of interpreters (Doefert \& Wilcox 1986; Rudser \& Strong 1986). The question of objective versus subjective assessment of interpreters, when evaluated by raters, is also addressed empirically in this decade (Strong \& Rudser 1986).

\subsection{Methodologies of the $1980 \mathrm{~s}$}

As is the case with all the studies examined here, the twenty-four 1980s studies are empirical, data-based research. As can be seen in Table 3.2 below, the methodological strategies pursued during the 1980s are more diverse than in the previous decade. While quantitative research represents $79 \%$ of these studies, this decade sees an increase in both the use of a qualitative methodology (33\%) and a combination of the two ("mixed method", see Creswell 2003) at 17\%. Further, an increase can be seen in both the use of survey-based data and naturalistic data during the 1980 s, from $20 \%$ and $10 \%$ respectively in the 1970 s to $33 \%$ and $21 \%$ respectively in the 1980 s. Finally, the relative use of experimental methods drops significantly in this decade, from $80 \%$ in the 1970 s to $33 \%$ in the 1980 s. 
Table 6: Empirical studies of SLI: 1980s methodology.

\begin{tabular}{|c|c|c|c|}
\hline $\mathbf{N}=\mathbf{2 4}$ & $\#$ & $\mathbf{\%}$ \\
\hline \multirow{4}{*}{ Method } & Quantitative & 19 & $79 \%$ \\
\cline { 2 - 4 } & Qualitative & 8 & $33 \%$ \\
\cline { 2 - 4 } & Mixed method & 4 & $17 \%$ \\
\cline { 2 - 4 } & Survey & 8 & $33 \%$ \\
\cline { 2 - 4 } & Experimental & 8 & $33 \%$ \\
\cline { 2 - 4 } & Naturalistic & 5 & $21 \%$ \\
\hline
\end{tabular}

The emergence of qualitative studies during the 1980s is significant. During the 1980 s, three of the studies are discourse-based and steeped in a sociolinguistic framework.

Winston (1989) conducts a qualitative analysis of discourse strategies in a case study using naturalistic data involving a more literal interpretation ("transliteration") of a classroom lecture. In another case study, Zimmer (1989) analyzes the English-only portion of an interpreted interview, comparing features such as pauses, fillers, and self-repair with those typical of non-interpreted interactive interviews. Roy (1989) examines the turn-taking exchanges in an interpreted meeting between a university professor and a student. These first two studies are relatively small in scope. Roy's study, however, is quite in-depth and offers a perspective new to the interpreting field regarding the role of community interpreters. She finds that, contrary to a popularly held belief that interpreters are neutral and, therefore, mere conduits of communication between primary participants, interpreters must take an active and participatory role within the interaction, or else the interpreted event could not proceed. The interpreter in Roy's study was successful in interpreting the interaction largely due to the active management of turn-exchanges. This seminal work is described as one of the two studies turning the tide from a target-text oriented paradigm to a discourse-based interactive paradigm within community interpreting.

\subsection{Countries represented during the $1980 \mathrm{~s}$}

Of the studies located from the 1980 s, $92 \%$ represent studies by and about SL interpreters in the US with only one other country, the UK, represented in this sample. 
Table 7: Empirical studies of SLI: 1980s countries represented.

\begin{tabular}{|c|c|c|c|}
\hline \multicolumn{2}{|c|}{$\mathbf{N}=\mathbf{2 4}$} & $\#$ & $\%$ \\
\hline \multirow{2}{*}{ Countries } & UK & 1 & $4 \%$ \\
\cline { 2 - 4 } & US & 22 & $92 \%$ \\
\hline
\end{tabular}

The UK study focuses on simultaneous interpretation, using an experimental methodology to analyze an interpretation from a recorded source to a live deaf audience (Llewellyn-Jones 1981). Because the focus of this study seems to be more on the relevance of meaning over that of form, and less on cognitive processing, it seems to reflect the Interpretive Theory of Translation paradigm.

\subsection{Paradigms represented in the 1980s}

Where the studies in the 1970s represented only two of the five paradigms Pöchhacker (2004) describes, all five are represented during the 1980s. Two of the studies during the 1980s fit the Interpretive Theory of Translation paradigm, the first being the study from the UK mentioned in the previous section, the other an examination of register in a commercially produced training video consisting of two lectures in American Sign Language being interpreted into English. In this study, Shaw (1987) examines indicators of register in both the source and target texts. Although it is somewhat experimental and is quantitatively based, this study is categorized within the Interpretive Theory of Translation tradition because of its emphasis on sense making and transference of meaning.

Also noteworthy in this decade is that one study fits the neurolinguistic paradigm. Although this study is not experimental in design, the purpose of the study is to examine brain dominance via the Herrmann Brain Dominance Instrument (in addition to other characteristics), based on a study of 400 nationally certified SL interpreters in the US. (Kanda 1989). 
Table 8: Empirical studies of SLI: 1980s paradigms.

\begin{tabular}{|c|c|c|c|}
\hline $\mathbf{N}=\mathbf{2 4}$ & $\#$ & $\mathbf{\%}$ \\
\hline \multirow{4}{*}{ Paradigm } & $\begin{array}{c}\text { Interpretive Theory of } \\
\text { Translation }\end{array}$ & 2 & $8 \%$ \\
\cline { 2 - 4 } & Neurolinguistic & 1 & $4 \%$ \\
\cline { 2 - 4 } & $\begin{array}{c}\text { Cognitive Processing } \\
\text { translational-theoretical approach }\end{array}$ & 4 & $17 \%$ \\
\cline { 2 - 4 } & Discourse-based Interaction & 2 & $83 \%$ \\
\hline
\end{tabular}

Table 8 indicates that there is little change in the percentage of studies reflecting the Cognitive Processing paradigm (17\% in the 1980 s as compared with $20 \%$ in the previous decade). While the number of Target-Text-Oriented studies remains the same in the 1980s, the percentage drops from over three-quarters to under half (33\%). The beginnings of a Discourse-based Interaction paradigm can be seen in this decade, with seminal studies that affect both signed and spoken language interpreting studies in subsequent decades as well.

\subsection{Summary of the $1980 \mathrm{~s}$}

Of the 97 studies located over the past four decades, those from the 1980s represent nine different topics of examination, including two topics not addressed in earlier studies. The 1980s also see an expansion of methodological approaches, from only quantitative to also qualitative and mixed method strategies. In addition there is an increase in the occurrence of survey and naturalistic data over experimental designs.

The current examination finds both UK and US researchers undertaking empirical research, and all five paradigms represented in the 1980s. Moreover, several seminal studies appear in this decade. Cokely (1985) contributes a sociolinguistically sensitive model to questions of cognitive processing by interpreters. Winston (1989) qualitatively examines "transliteration" and identifies features of language contact that serve to set the standard for professional testing for some years to come. Roy (1989) conducts a seminal study of interactive interpretation that contributes to a shift in paradigm that is more sociolinguistically sensitive in its discourse-based approach to examining interpreted interaction. Finally, studies of SLI in the 1980 s reveal that while scholarship in this field is comparable to community interpreting scholarship within the spoken language interpreting community, the timing and sequence of studies as they reflect various paradigms may not parallel that of spoken language interpretation. 


\section{Empirical studies of SLI: 1990s}

Examination of empirical SLI studies from the 1990s reveals yet more changes. A total of 27 of the 97 studies occur during the 1990s, representing once again a larger number of topics. Furthermore, a shift can be seen in terms of methodological strategies and paradigms with once more a slightly larger geographical area represented, though most of the studies identified in the 1990s still come from the US.

\subsection{Topics of the $1990 \mathrm{~s}$}

Nine topics from the 1980 s are also represented during the 1990 s with an additional two topics: medical interpreting and legal interpreting.

Table 9: Empirical studies of SLI: 1980s topics.

\begin{tabular}{|c|c|c|c|}
\hline $\mathbf{N}=\mathbf{2 7}$ & $\#$ & $\mathbf{\%}$ \\
\hline \multirow{4}{*}{} & $\begin{array}{c}\text { Interpreter } \\
\text { Effectiveness/Characteristics }\end{array}$ & 6 & $22 \%$ \\
\cline { 2 - 4 } & Source-to-Target Comparison & 7 & $26 \%$ \\
\cline { 2 - 4 } & Cognitive Processing & 2 & $7 \%$ \\
\cline { 2 - 4 } & $\begin{array}{c}\text { Language contact: } \\
\text { free vs literal }\end{array}$ & 7 & $26 \%$ \\
\cline { 2 - 4 } & $\begin{array}{c}\text { Interpreter Education and/or } \\
\text { Assessment }\end{array}$ & 4 & $15 \%$ \\
\cline { 2 - 4 } & $\begin{array}{c}\text { Working Conditions/ } \\
\text { Occupational Safety }\end{array}$ & 4 & $15 \%$ \\
\cline { 2 - 4 } & $\begin{array}{c}\text { Interpreter's Role/ } \\
\text { Professional Code of Ethics }\end{array}$ & 2 & $7 \%$ \\
\cline { 2 - 4 } & \begin{tabular}{c} 
Educational Interpreting \\
\cline { 2 - 4 }
\end{tabular} & 6 & $22 \%$ \\
\cline { 2 - 4 } & Conference Interpreting & 1 & $6 \%$ \\
\cline { 2 - 4 } & Medical Interpreting & 2 & $9 \%$ \\
\cline { 2 - 4 } & Legal Interpreting & 1 & $6 \%$ \\
\hline
\end{tabular}

Of the eleven topics represented during this decade, the most common topics are source-to-target comparisons and language contact, i.e. free vs literal interpretation. These two topics have been of interest throughout all three decades of research. The second most popular topics are interpreter effectiveness and characteristics, and educational interpreting. Once again, these two topics have consistently been examined since the earliest studies in the 1970s. The third most common topics of research in this decade are interpreter training and assessment, and working conditions/occupational safety. 
While the former has received some attention throughout all three decades, the latter only appeared in a small way during the 1980s.

Three studies during the 1980s examine working conditions and occupational safety. Feuerstein et al. (1997) conduct a survey of 1398 SL interpreters on occupational musculoskeletal health, including demographic information as well as information about work environment, work style, medical care, and symptoms. Kimmel (1996) conducts a survey to examine the relationship between work style and the perception of control, fear of pain, muscle tension and other contributors to work-related injuries for SL interpreters. However, Peper and Gibney (1999) apply an experimental design to the issue of occupational safety, through an examination of psychophysiological evidence of stress while engaged in the interpreting process. This quantitative study offers a unique examination of this topic, and is the first of the studies identified to pursue a research design that is not survey-based.

Medical interpreting is the next most common topic of the studies examined from this decade. Brener (1991) combines the question of interpreter effectiveness with the medical setting in a study of 53 deaf, signing adults and 4 hearing, English-speaking optometrists. This experimental study compared the use of SL interpreters with the use of written notes and other non-interpreted communication strategies (including lipreading, for example). This study underscores a point made earlier in this paper. Often, for SL interpreters, at least one of the primary participants might be bilingual. Nevertheless, communication via an interpreter or pencil and paper can be quite different in terms of length of interaction, details of information exchanged, and other socio-cultural and sociolinguistic factors. This study determines that SL interpreters clearly affect linguistic accessibility, but do not significantly impact the information exchange or affective communication. Further research regarding the distinction between "information exchange" and "linguistic accessibility" could be useful.

Where Brener's study is experimental in design, Metzger (1995) examines an interpreted medical encounter using naturalistic data and a strongly qualitative, mixed methodology. Unlike Brener, Metzger's study focuses on the participation framework within the medical encounter, following in the discourse-based interactional tradition established by Roy (1989) and Wadensjö (1992). Like Roy and Wadensjö, Metzger finds that the interpreter does not simply translate utterances, but also makes interpreter-generated contributions to the interaction. These fall into two categories: relayings and interactional management. Metzger argues that without these contributions the event would lack interactional equivalence. For example, primary participants might not know which primary party was responsible for which translated utterances.

Because of the focus on the participation framework, Metzger's study touches also on the topic of the interpreter's role and professional code of ethics. Cognitive processing and the interpreter's role and professional code of ethics, are the next most common topics in 1980 s empirical studies. It is noteworthy that cognitive processing represents only $7 \%$ of the 
studies in this decade, a drop from $17 \%$ in the previous decade. Finally, conference interpreting and legal interpreting each represent $6 \%$ of the 27 studies from this decade. The study on legal interpreting examines the translation of lexical tense markers between English and American Sign Language in a deposition, providing evidence from a case in which tenserelated errors in translation led to a faulty outcome.

\subsection{Methodologies of the $1990 \mathrm{~s}$}

As is the case with all the studies examined here, the 271980 s studies are empirical, data-based research. Table 10 below shows that the methodological strategies pursued during the 1980s are more diverse than in the previous decade. While quantitative research remains at about the same percentage at $78 \%$, this decade sees an increase in both the use of a qualitative methodology, from a third of the studies in the 1980s to over half of the 1980s studies. An increase can also be seen in the use of mixed methods, from less than a quarter of the studies in the 1980s to a third of the 1980 s studies. Further, a slight increase can be seen in the use of survey-based data in the 1980s (from 33\% to 37\%) and a decrease in naturalistic data during the 1980 s (from $21 \%$ to $15 \%$ ), while the use of experimental design remains the same $(33 \%)$.

Table 10: Empirical studies of SLI: 1980s methodology.

\begin{tabular}{|c|c|c|c|}
\hline $\mathbf{N}=\mathbf{2 7}$ & $\#$ & $\mathbf{\%}$ \\
\hline \multirow{4}{*}{ Method } & Quantitative & 21 & $78 \%$ \\
\cline { 2 - 4 } & Qualitative & 15 & $56 \%$ \\
\cline { 2 - 4 } & Mixed method & 9 & $33 \%$ \\
\cline { 2 - 4 } & Survey & 10 & $37 \%$ \\
\cline { 2 - 4 } & Experimental & 9 & $33 \%$ \\
\cline { 2 - 4 } & Naturalistic & 4 & $15 \%$ \\
\hline
\end{tabular}

\subsection{Countries represented in the 1990s}

Of the studies located from the 1990s, 93\% represent studies by and about SL interpreters in the US, which is consistent with the percentage representing the US in the previous decade. Two studies of other countries are represented in this sample of studies: Austria (Grbić 1994) and the UK (Kyle \& Allsop 1997). 
Table 11: Empirical Studies of SLI: 1980s Countries Represented

\begin{tabular}{|c|c|c|c|}
\hline \multicolumn{2}{|c|}{$\mathbf{N = 2 7}$} & $\#$ & $\%$ \\
\hline \multirow{3}{*}{ Countries } & Austria & 1 & $4 \%$ \\
\cline { 2 - 4 } & UK & 1 & $4 \%$ \\
\cline { 2 - 4 } & U.S. & 25 & $93 \%$ \\
\hline
\end{tabular}

The UK study consists of a survey of institutions in Sweden, Ireland, Denmark and the UK, as well as France, Italy, Spain, Portugal, and Austria; with the former group more inclined to utilize SL interpreters than the latter. This study was commissioned by the European Union of the Deaf to examine the use of SL and SL interpreters in Europe. Grbic reports on a study of Austrian SL interpreters and discusses information gathered in terms of curriculum design.

\subsection{Paradigms represented in the $1990 \mathrm{~s}$}

Where the studies in the 1980s represented all five paradigms, the 1980s studies represent only three (Cognitive Processing, Target-Text Oriented and Discourse-based Interaction). The first two have been consistent since the earliest studies in the 1970s and are complemented now in the 1980s with the addition of the third paradigm that emerged in the 1980s, the Discourse-based Interaction tradition of scholarship.

The fact that none of the 1990s studies represent the Interpretive Theory of Translation may be related to the fact that it focuses primarily on conference interpreting, which was seen to represent only a relatively small percentage of topics examined $(6 \%)$. Of the three paradigms that are represented in the 1990s, there is some shift in the occurrence of each paradigm in contrast with the preceding decade. Cognitive Processing decreased from $17 \%$ to $11 \%$; the Target-text Oriented tradition increased from $33 \%$ to $41 \%$, and Discourse-based Interaction increased from $8 \%$ to $15 \%$. The $1980 \mathrm{~s}$ studies thus reflect an overall shift from information processing to a focus more on discourse and social issues related to community interpreting. 
Table 12: Empirical Studies of SLI: 1990s Paradigms

\begin{tabular}{|c|c|c|c|}
\hline $\mathbf{N}=\mathbf{2 7}$ & $\#$ & $\mathbf{\%}$ \\
\hline \multirow{4}{*}{ Paradigm } & $\begin{array}{c}\text { Interpretive Theory of } \\
\text { Translation }\end{array}$ & - & - \\
\cline { 2 - 4 } & Neurolinguistic & - & - \\
\cline { 2 - 4 } & Cognitive Processing & 3 & $11 \%$ \\
\cline { 2 - 4 } & $\begin{array}{c}\text { Target-Text oriented } \\
\text { translational-theoretical approach }\end{array}$ & 11 & $41 \%$ \\
\cline { 2 - 4 } & Discourse-based Interaction & 5 & $19 \%$ \\
\hline
\end{tabular}

In the 1990s, 11 studies deal with aspects that are not directly covered by the five paradigms. Two studies (7\%) discuss assessment, 6 discuss characteristics of interpreters $(22 \%)$, and 3 study occupational safety $(11 \%)$. For example, Simon (1994) conducts an ethnographic analysis of interpreter training programmes; the Grbić (1994) study of Austrian interpreters and other studies such as Burch (1999) are heavily demographic in their survey design; and the studies by Feuerstein et al (1997) and Kimmel (1996) deal with occupational safety issues.

\subsection{Summary of the 1990s}

The studies from the 1990s represent eleven different topics, reflecting an increase in the use of qualitative and mixed method research design. Further, the diversity of topics continues to expand, with a more detailed interest in particular settings within the scope of community interpreting. In earlier decades, interpretation was studied with experimental data, often with pre-recorded source tapes. By the 1990s, an increase in naturalistic data emerges, allowing interpreting researchers to narrow the scope of their studies from "interpretation" to "legal interpretation" or "medical interpretation."

As in the 1980s, a very slight increase can be seen regarding the number of countries represented. However, there is a decrease in studies representing diverse scholarly traditions, and a shift in focus from an emphasis on interpretation and information processing from a cognitive or psycholinguistic perspective, to a focus on interpretation as a social event, with an increase in studies representing the Target-text Oriented and Discoursebased Interaction traditions.

During the 1990s, a number of studies are noteworthy. For example, Davis (1990a, 1990b) continues the examination of language contact within ASL-English interpretation, Metzger's (1995) study follows Roy (1989) in a Discourse-based Interactional tradition, analyzing interpreted interaction from a sociolinguistic perspective. Siple (1995) follows Winston (1989), selecting one of five features identified in Winston's study of literal interpre- 
tation and examining that feature in greater detail using a quantitative methodology. Finally, Ressler (1999) conducts a study of interpreting teams that is quite unique. First, because studies of team interpreting are long overdue, given that the earliest studies in the 1970s already include a discussion of the need for limited time frame for interpreters to avoid compromising the quality of their work due to fatigue (Babbini 1976). Second, while SL interpreters, like any interpreter, must be bilingual (or multilingual), bilinguals who are fluent in an SL might be deaf or hearing. Ressler's study examines team interpreting in which one of the interpreters is deaf and the other hearing.

\section{Empirical studies of SLI: 2000-2005}

The 37 empirical SLI studies between the shorter time-span of 2000-2005 reveal yet more changes and a slightly larger number of topics from the decade preceding. Once again a shift can be seen in terms of methodological strategies and paradigms and a slightly larger geographical area is represented.

\subsection{Topics from 2000-2005}

One new topic appears between 2000-2005, increasing the 11 of the 1990s to 12. This new topic - religious interpreting - introduces a qualitative, naturalistic study of question-answer adjacency pairs in an ASL sermon (Richey 2003). 
Table 13: Empirical studies of SLI: 2000s topics.

\begin{tabular}{|c|c|c|c|}
\hline $\mathbf{N}=\mathbf{3 7}$ & $\#$ & $\mathbf{\%}$ \\
\hline \multirow{1}{*}{} & $\begin{array}{c}\text { Interpreter } \\
\text { Effectiveness/Characteristics }\end{array}$ & 11 & $30 \%$ \\
\cline { 2 - 4 } & Source-to-Target Comparison & 9 & $24 \%$ \\
\cline { 2 - 4 } & Cognitive Processing & 3 & $8 \%$ \\
\cline { 2 - 4 } & $\begin{array}{c}\text { Language contact: } \\
\text { free vs literal }\end{array}$ & 9 & $24 \%$ \\
\cline { 2 - 4 } & $\begin{array}{c}\text { Interpreter Education and/or } \\
\text { Assessment }\end{array}$ & 4 & $11 \%$ \\
\cline { 2 - 4 } & $\begin{array}{c}\text { Working Conditions/ } \\
\text { Occupational Safety }\end{array}$ & 1 & $3 \%$ \\
\cline { 2 - 4 } & $\begin{array}{c}\text { Interpreter's Role/ } \\
\text { Professional Code of Ethics }\end{array}$ & 8 & $22 \%$ \\
\cline { 2 - 4 } & Educational Interpreting & 8 & $22 \%$ \\
\cline { 2 - 4 } & Conference Interpreting & 3 & $8 \%$ \\
\cline { 2 - 4 } & Medical Interpreting & 2 & $5 \%$ \\
\cline { 2 - 5 } & Legal Interpreting & 3 & $8 \%$ \\
\cline { 2 - 4 } & Religious Interpreting & 1 & $3 \%$ \\
\hline
\end{tabular}

The breakdown of topics between 2000-2005 is in many ways similar to that of the 1990s. The percentage of studies in the areas of Source-to-Target Comparison, Cognitive Processing, Language contact: free vs literal, Interpreter Education and/or Assessment, Educational Interpreting, Conference Interpreting, Medical Interpreting, and Legal Interpreting remain nearly the same (with variations less than $5 \%$ up or down). Interpreter Effectiveness/Characteristics, however, shifts from less than one fourth to nearly a third of the studies in the current time period, Working Conditions/Occupational Safety decreases from $15 \%$ in the 1990 s to only $3 \%$, and Interpreter's Role/Professional Code of Ethics increases from 7\% in the 1990 s to nearly one fourth of the studies in this period $(22 \%)$. Notably, one of the studies of interpreter effectiveness and characteristics addresses consumer satisfaction regarding the relatively new and increasingly popular use of video conferencing to connect SL interpreters to events from a distance (see Steinberg 2003). An area that also is worthy of examination is the use of video relay services that provide interpreters for deaf and hearing callers via videophone technology.

Of the studies related to cognitive processing, two are worth mentioning due to their seminal impact on both interpreting research and practice. One, a Canadian study on legal interpreting examines the role of simultaneous and consecutive modes in legal settings, indicating that these 
modes must be carefully selected and applied within the legal process (Russell 2000). The second (Napier 2002a) is a study of omissions in interpreted target texts from a university lecture source, typically examined as a type of error associated with cognitive processing (for instance, insufficient lag time), and does so from a Discourse-based Interactional perspective in which the omissions are categorized based on how aware the interpreter is of them, and how intentional the omissions are. Napier finds that interpreters make intentional omissions that are strategically designed to support the quality of their target texts, in addition to other types of omissions (including those omissions of which the interpreter is not even aware). These two studies have significant implications regarding interpreter practice, the training of interpreters, and raise questions for further research.

\subsection{Methodologies between 2000-2005}

The methodological approaches in the 2000-2005 studies are similar to those of the 1990s. In terms of quantitative, qualitative, and mixed methods, as well as the percentage of studies that are survey-based or naturalistic, the shifts are small (less than 5\%). However, the percentage of experimental studies drops from a third to less than one fourth between 2000-2005.

Table 14: Empirical studies of SLI: 2000s methodology.

\begin{tabular}{|l|c|c|c|}
\hline $\mathbf{N}=37$ & $\#$ & $\%$ \\
\hline \multirow{4}{*}{ Method } & Quantitative & 28 & $76 \%$ \\
\cline { 2 - 4 } & Qualitative & 22 & $60 \%$ \\
\cline { 2 - 4 } & Mixed method & 13 & $35 \%$ \\
\cline { 2 - 4 } & Survey & 14 & $38 \%$ \\
\cline { 2 - 4 } & Experimental & 7 & $19 \%$ \\
\cline { 2 - 4 } & Naturalistic & 7 & $19 \%$ \\
\hline
\end{tabular}

\subsection{Countries represented between 2000-2005}

The largest increase in number of countries represented occurs in this period. Seven different countries are represented (with one study actually focusing internationally). 
Table 15: Empirical studies of SLI: 2000s countries represented.

\begin{tabular}{|c|c|c|c|}
\hline $\mathbf{N}=\mathbf{3 7}$ & $\#$ & $\mathbf{\%}$ \\
\hline \multirow{4}{*}{ Countries } & Australia & 5 & $14 \%$ \\
\cline { 2 - 4 } & Belgium & 1 & $3 \%$ \\
\cline { 2 - 4 } & Canada & 2 & $5 \%$ \\
\cline { 2 - 4 } & International & 1 & $3 \%$ \\
\cline { 2 - 4 } & Sweden & 1 & $3 \%$ \\
\cline { 2 - 4 } & UK & 3 & $8 \%$ \\
\cline { 2 - 4 } & U.S. & 24 & $65 \%$ \\
\hline
\end{tabular}

The country most frequently represented in this period is the US $(65 \%)$ with Australia coming in second (14\%). Just under one fourth of the studies are spread between the remaining countries represented: UK (8\%), Canada (5\%), and Belgium, Sweden, and an international study (all at 3\%). The international study is a mixed method survey of 12 countries that compares their Code of Ethics for SL interpreters (Rodriguez \& Guerrero 2002). Tate \& Turner (2001) also address the issue of interpreter role and ethics in a study conducted in the UK. International studies touch on a variety of topics such as legal interpreting in a Canadian and a UK study (Russell 2000; Turner \& Taylor 2001). Qualitative research, while less common in those studies examined from earlier decades in the US, can be seen in other countries. Harrington (2005), for example, discusses a qualitative analysis of interpreters working in post-secondary settings in the UK.

\subsection{Paradigms represented between 2000-2005}

As in the 1990 s, the paradigms reflected by $2000-2005$ studies represent only three traditions: Cognitive Processing, Target-Text Oriented, and Discourse-based Interaction. Both Cognitive Processing and Discourse-based Interaction retain a consistent percentage with the previous decade (within $5 \%$ ). The Target-Text Oriented approach, however, increases from $41 \%$ to $51 \%$. 
Table 16: Empirical studies of SLI: 2000s paradigms.

\begin{tabular}{|c|c|c|c|}
\hline $\mathbf{N}=\mathbf{3 7}$ & $\#$ & $\mathbf{\%}$ \\
\hline \multirow{4}{*}{ Paradigm } & $\begin{array}{c}\text { Interpretive Theory of } \\
\text { Translation }\end{array}$ & - & - \\
\cline { 2 - 4 } & Neurolinguistic & - & - \\
\cline { 2 - 4 } & $\begin{array}{c}\text { Cognitive Processing } \\
\text { translational-theoretical approach }\end{array}$ & 5 & $14 \%$ \\
\cline { 2 - 4 } & Discourse-based Interaction & 6 & $51 \%$ \\
\hline
\end{tabular}

The increase over time of the Target-text oriented paradigm may well reflect the subjective analysis of the author on how to assess these studies in terms of Pöchhacker's paradigmatic analysis. At the same time, these studies, throughout all four time periods, clearly reflect a heavy emphasis within SLI studies on comparisons between source and target texts, and free versus literal interpretations (interpretations as compared with so-called "transliterations" resulting from heavy language contact between deaf and hearing communities).

\subsection{Summary of 2000-2005}

The studies between 2000-2005 represent twelve different topics and all methodological approaches. Perhaps the most notable shift in this period is the increase in studies from a variety of countries, representing seven different countries (with one actually an international study of 12 countries) in only half a decade. On the other hand, the changes between the 1990s and the 2000-2005 time period seem to be more stable than the changes between previous decades, with more consistency in terms of topics, research methods, and research traditions. During this period a number of studies also follow up on previous seminal works. For example, Cerney (2005) examines deaf-hearing interpreter teams in a mixed methods examination of naturalistic data taken from conference interpreting, a topic that first appeared in the 1980s in an experimental study of deaf-hearing interpreter teams (Ressler 1999). This topic is noteworthy when comparing it with spoken language interpretation because of the interpreter language background. For interpreters who are deaf, their first language is generally a signed one, whereas this is not always the case for hearing interpreters. Examination of deaf-hearing teams relates to spoken language interpreters' questions about interpreting into or out of their A language, an issue which is somewhat unique within SLI practice. ${ }^{6}$ Similarly, Collins (2004) examines language contact and variation as it relates to interpreting between deaf sighted and deaf blind consumers, focusing on the analysis of non-manual (facial) grammatical information and how that grammatical information is con- 
veyed manually via tactile American Sign Language. This is another area in which it is common to see deaf SL interpreters at work. Also, in this period, there is another study of quality issues in (hearing-hearing) team interpreting (Cokely and Hawkins 2003).

During this time period Davis (2003) continues his examination of language contact within SLI. Winston's (1989) seminal case study of the features of literal interpretations is replicated in an examination of Swedish SL interpretation (Detthow 2000). There is an increase in the examination of consumer perceptions (Forestal 2005; King 2001; Steinberg 2003). Several studies follow up on the work of Roy (1989) and Metzger (1995), including Metzger, Fleetwood \& Collins' (2004) study of discourse genre and linguistic mode and the contributions to discourse made by interpreters within medical, classroom, and information interviews; Sanheim's (2003) study of turn-exchanges within a medical interview; Sofinski et al (2001) and Sofinski's (2003) studies of the features of literal interpretations, following Winston (1989); and Winston \& Monikowski's (2003) study of free and literal interpretations, also following Winston's (1989) seminal study. The five-year period from 2000-2005 is thus rich with scholarship that builds upon previous studies.

\section{Conclusion}

This paper set out to examine data-based studies of SLI to highlight seminal work within this field and to contextualize this within the larger framework of interpreting scholarship. A huge task at best, though the examination was constrained by both data sources (an international bibliography and a professional journal) and availability. This paper therefore offers but a snapshot of what has been gleaned thus far, with studies compared over time (by decade) and grouped on the basis of topic, research method, country, and research paradigm.

The earliest studies of SLI focus on the topic of interpreter effectiveness and the characteristics of interpreters, with source-to-target comparisons as the second most popular topic. Interestingly, these two topics consistently remain the first and second most studied throughout the four decades under examination. While other topics might be affected by language pair or mode, by country of origin etc., the results of this study suggest that, over time, the quality of the work interpreters perform and the qualities that allow that work to take place, are of utmost importance within the field of SLI.

The earliest studies of SLI demonstrate a clear preference for quantitative methodology. Over time, this preference has not disappeared. At the same time, a clear increase in qualitative and mixed methods can be seen as well.

Although the bulk of the studies examined here come from the international SL bibliography, housed in Europe at the University of Hamburg, still the bulk of the studies represent the US in either geographical location 
or corpus of data. Based on the empirical studies examined here, US studies have clearly dominated the field, with a slow shift toward diversity.

Of the scholarly traditions represented here, few represent the Interpretive Theory of Translation. However, as in spoken language interpretation, the cognitive processing tradition is present throughout this period in SLI and these studies seem to support findings of similar studies from within the area of spoken language interpreting.

Neurolinguistic studies of SLI are extremely rare, with only one among the 97 studies. On the other hand, the percentage of studies based on the Target-Text Oriented tradition is very high. This is the most heavily represented paradigm of the studies examined here. It is quite possible that this heavy occurrence is related, in part, to the larger number of community interpreting studies (larger, that is, than the number of studies of conference interpreting). ${ }^{7}$ Finally, the Discourse-based Interaction paradigm is the newest, and is enjoying an increase in application, particularly as this paradigm is associated with two seminal studies, one of which is from the field of SLI (Roy 1989).

Earlier in this paper it was noted that Roberts (1987) suggests both similarities and differences between spoken language and SL interpretation. Roberts suggests, for example, that spoken language interpreters tend to be associated with conference interpreting whereas SL interpreters work more often in community settings. However, this paper (and indeed, the articles in this journal) suggests that this distinction is probably no longer the case. That is, today spoken language interpreters frequently work in a variety of community settings, and conversely, SL interpreters often work at conferences. Roberts also proposes that a difference between spoken and SL interpretation results from the difference in mode. This difference, combined with the fact that SL interpreters often work with at least one primary participant who is bilingual in both languages of the interaction, does seem to contribute to a heavy emphasis in the 97 studies examined here on language contact and free versus literal interpretation. This sociolinguistic issue is also related to a whole history of language attitudes and language policies that affect the lives of deaf people around the globe, and therefore, the work of SL interpreters. Perhaps this sociolinguistic issue also accounts for any distinction that might have once existed in prestige between interpreters working with spoken or signed languages. Moreover, in closer analyses of specific language communities and language pairs, it is likely that the issue of prestige among interpreters varies more by linguistic community than by mode. The 97 studies examined in this paper suggest that mode makes far less difference than one might expect, when it comes to issues such as cognitive processing and socio-cultural mediation.

Having examined these 97 studies, two points have become clear. First, the comparison and analysis of interpretation from a variety of perspectives is quite interesting, regardless of whether the breakdown be diachronic, topically-based, methodologically oriented, or based on scholarly tradition. Second, it also appears to be true, however, that ultimately, whether the differences between interpreters are based on mode, languages, coun- 
try, work setting, or paradigm, the work we do seems to have a thread that ties us all together. The cognitive, social, cultural, and linguistic activities in which we engage unite interpreters whether they work in conference or community settings, or work as spoken or signed language interpreters.

\section{Bibliography}

Babbini, B. (1976). "The effects of fatigue on the the competence of interpreters for the deaf". H. Murphy (ed.). Selected Readings in the Integration of Deaf Students at CSUN. Northridge, CA: California State University, 19-22.

Brasel, B., D. Montanelli \& S. Quigley (1974). "The component skills of interpreting as viewed by interpreters". Journal of Rehabilitation of the Deaf 7(3), 20-32.

Brener, T. (1991). The relationship between the use of sign language interpreters and effectiveness of communication in a medical encounter. PhD thesis, Temple University.

Burch, D. (1999). Essential competencies, responsibilities, and education of sign language interpreters in pre-college educational settings. Phd thesis, Southern University and A \& M College.

Cerney, B. (2005). Relayed interpretation from English to American Sign Language via a hearing and a deaf interpreter. Phd thesis, The Union Institute and University.

Cokely, D. (1985). Towards a sociolinguistic model of the interpreting process. Phd thesis, Georgetown University.

Cokely, D. \& J. Hawkins. (2003). "Interpreting in teams: A pilot study on requesting and offering support". Journal of Interpretation, 49-93.

Collins, S. (2004). Adverbial morphemes in tactile ASL (TASL). Phd thesis, The Union Institute and University.

Creswell, J. (2003). Research design: Qualitative, quantitative, and mixed methods approaches. Thousand Oaks: Sage.

Davis, J. (1990a). Interpreting in a language contact situation: The case of English-to-ASL interpretation. Phd dissertation, University of New Mexico.

Davis, J. (1990b). "Linguistic transference and interference: Interpreting between English and ASL”. C. Lucas (ed). Sign Language Research: Theoretical Issues. Washington, DC: Gallaudet University Press, 308-324.

Davis, J. (2003). "Cross-linguistic strategies used by interpreters". Journal of Interpretation, 95128.

Detthow, A. (2000). "Transliteration between spoken Swedish and Swedish signs". M. Metzger (ed.). Bilingualism and Identity in Deaf Communities. Washington, DC: Gallaudet University Press, 79-92.

Doefert, K. \& S. Wilcox. (1986). "Meeting students affective needs: Personality types and learning preferences". Journal of Interpretation 3, 35-45.

Fabbro, F. \& L. Gran. (1994). "Neurological and neuropsychological aspects of polyglossia and simultaneous interpretation.". S. Lambert \& B. Moser-Mercer (eds). Bridging the Gap: Empirical Research in Simultaneous Interpretation. Amsterdam/Philadelphia: John Benjamins, 273-317.

Fabbro, F., L. Gran, G. Basso \& A. Bava. (1990). "Cerebral lateralization in simultaneous interpretation". Brain and Language 39, 69-89.

Feuerstein, M., A. Carosella, L. Burrell, L. Marshall, and J. DeCaro (1997). "Occupational upper extremity symptoms in sign language interpreters: Prevalence and correlates of pain, function, and work disability". Journal of Occupational Rehabilitation 7(4), 187-205.

Finnegan, M. (1986). Interpreter effectiveness in sign-to-voice interpreting for deaf children. Phd dissertation, Temple University.

Fleischer, L. (1975). Sign language interpretation under four interpreting conditions. Phd dissertation, Brigham Young University.

Fleischer, L. \& M. Cottrell. (1976). "Sign language interpretation under four interpreting conditions". H. Murphy (ed.). Selected Readings in the Integration of Deaf Students at CSUN. Northridge, CA: California State University, 23-26.

Forestal, L. (2005). "Attitudes of Deaf leaders toward signed language interpreters and interpreting". M. Metzger and E. Fleetwood (eds). Attitudes, Innuendo, and Regulators: Challenges of Interpretation, vol. 2. Washington, DC: Gallaudet University Press, 71-91.

Gerver, D. (1976). "Empirical studies of simultaneous interpretation: A review and a model". R.W. Brislin (ed). Translation: Applications and Research. New York: Gardner Press, 165-207. 
Gile, D. (1990). "Scientific theories vs. personal theories in the investigation of interpretation". L. Gran \& C. Taylor (eds). Aspects of Applied and Experimental Research on Conference Interpretation. Udine: Campanotto, 28-41.

Gile, D. (1995). Basic concepts and models for interpreter and translator training. Amsterdam/Philadelphia: John Benjamins.

Gish, S. (1986). “'I understood all the words but I missed the point': A Goal-to detail/detail-to-goal strategy for text analysis".

Grbić, N. (1994). Das Gebärdensprachdolmetschen als Gegenstand einer angewandten Sprachund Translationswissenschaft unter besonderer Berücksichtigung der Situation in Osterreich. Phd dissertation, University of Graz.

Greenhaw, D. (1985). "Post-secondary education survey of interpreter services: A statistical study". Journal of Interpretation 2, 40-57.

Gustason, G. (1985). "Interpreters entering public school employment". American Annals of the Deaf. 130 (4): 265-266.

Harrington, F. (2005). A study of the complex nature of interpreting with Deaf students in higher education. M. Metzger \& E. Fleetwood (eds). Attitudes, Innuendo, and Regulators: Challenges of Interpretation, vol. 2. Washington, DC: Gallaudet University Press, 162187.

Kanda, J. (1989). Characteristics of certified sign language interpreters including patterns of brain dominance. PhD dissertation, Brigham Young University.

Kimmel, D. (1996). The relationships between perception of control,anticipatory anxiety, fear of pain from work injury, muscle tension and pain during work, and the outcomes of workrelated diagnosis, dysfunction in daily activities, and work loss in interpreters for the deaf. Phd dissertation, The Union Institute and University.

King, S. (2001). Administrative and consumer perceptions of interpreting services at postsecondary programs for deaf students. Phd dissertation, Gallaudet University.

Kirchoff, H. (1976/2000). "Simultaneous interpreting: Interdependence of variables in the interpreting process, interpreting models, and interpreting strategies”. F. Pöchhacker \& M. Shlesinger (eds). The Interpreting Studies Reader. 111-119.

Kyle, J. \& L. Allsop. (1997). Sign in Europe: A study of Deaf people and sign language in the European Union. Bristol: Centre for Deaf Studies, Univerity of Bristol.

LaVor, M. (1985). "Interpreters: The economic impact". Journal of Interpretation 2, 27-39.

Lederer, M. (1981). La traduction simultanée - Expérience et théorie. Paris: Minard Lettres Modernes.

Llewellyn-Jones, P. (1981). "Simultaneous interpreting". B. Woll \& J. Kyle (eds). Perspectives on British Sign Language and Deafness. London: Croom Helm Ltd, 89-103.

Metzger. M. (1995). The paradox of neutrality: A comparison of interpreters' goals with the realities of interactive discourse. Phd dissertation, Georgetown University.

Metzger, M. (1999) Sign language interpreting: Deconstructing the myth of neutrality. Washington, DC: Gallaudet University Press.

Metzger, M., E. Fleetwood \& S. Collins. (2004). "Discourse genre and linguistic mode: Interpreter influences in visual and tactile interaction”. Sign Language Studies. 4(2), 118-137.

Moser-Mercer, B. (1994). "Paradigms gained or the art of productive disagreement". S. Lambert \& B. Moser-Mercer (eds). Bridging the Gap: Empirical Research in Simultaneous Interpretation. Amsterdam/Philadelphia: John Benjamins, 17-23.

Murphy, H. \& L. Fleischer. (1976). "The effects of Ameslan vs Siglish upon test scores". H. Murphy (ed.). Selected Readings in the Integration of Deaf Students at CSUN. Northridge, CA: California State University, 27-28.

Napier, J. (2002a). Sign language interpreting: Linguistic coping strategies. Coleford, England: Douglas McLean.

Napier, J. (2002b). "University interpreting: Linguistic issues for consideration". Journal of Deaf Studies and Deaf Education 7(4), 281-301.

Napier, J. (2003). "A sociolinguistic analysis of the occurence and types of omissions produced by Australian Sign Language-English interpreters". M. Metzger, S. Collins, V. Dively, \& R. Shaw (eds). From Topic Boundaries to Omission: New Research on Interpretation, Studies in Interpretation, vol. 1. Washington, DC: Gallaudet University Press, 99-153.

Nida, E. (1964). Toward a science of translating with special reference to principles and procedures involved in Bible translating. Leiden: E. J. Brill.

Norwood. M. (1976). Comparison of an interpreted and captioned newscast among deaf high school graduates and deaf college graduates. Phd dissertation, University of Maryland.

Peper, E. \& K. Gibney. (1999). "Psychological basis for discomfort during sign language interpreting". Journal of Interpretation 11-18.

Pöchhacker, F. (1994). Simultandolmetschen als complexes Handeln. Tübingen: Gunter Narr. 
Pöchhacker, F. (2004). Introducing Interpreting Studies. London/New York: Routledge.

Ressler, C. (1999). "Direct interpretation and an intermediary interpretation". Journal of Interpretation, 71-102.

Richey, M. (2003). "Analysis of interactive discourse in an interpreted Deaf revival service: Question-Answer adjacency pairs initiated in an ASL sermon”. M. Metzger, S. Collins, V. Dively \& R. Shaw (eds). From Topic Boundaries to Omission: New Research on Interpretation, Studies in Interpretation, vol. 1. Washington, DC: Gallaudet University Press, 55-96.

Roberts, R. (1987). "Spoken language interpreting vs. sign language interpreting". Proceedings of the 28th Annual Conference of the American Translator's Association, 293-306.

Rodriguez, E. \& A. Guerrero. (2002). "An international perspective: What are ethics for sign language interpreters? A comparative study among different codes of ethics". Journal of Interpretation, 49-61.

Roy, C. (1989). A sociolinguistic analysis of the interpreter's role in the turn exchanges of an interpreted event. Phd dissertation, Georgetown University.

Roy, C. (2000). Interpreting as a discourse process. Oxford: Oxford University Press.

Rudser, S. (1986). "Linguistsic analysis of changes in interpreting: 1973-1985". Sign Language Studies 15(53), 332-340.

Rudser, S. \& M. Strong. (1986). "An examination of some personal characteristics and abilities of sign language interpreters”. Sign Language Studies 15(53), 315-331.

Russell, D. (2000). Interpreting in legal contexts: Consecutive and simultaneous interpretation. Phd dissertation, University of Calgary.

Sanheim, L. (2003). "Turn exchange in an interpreted medical encounter". M. Metzger, S. Collins, V. Dively \& R. Shaw (eds). From Topic Boundaries to Omission: New Research on Interpretation, Studies in Interpretation, vol. 1. Washington, DC: Gallaudet University Press. 27-54.

Schein, J. (1974). "Personality characteristics associated with interpreter proficiency". Journal of Rehabilitation of the Deaf 7(3), 33-43.

Seleskovitch, D. (1975/2002). "Language and memory: A study of note taking in consecutive interpreting". F. Pöchhacker \& M. Shlesinger (eds). The Interpreting Studies Reader. London/New York: Routledge. 121-129.

Seleskovitch, D. (1992). "In the beginning". Journal of Interpretation. 5(1), 1-4.

Shaw, R. (1987). "Determining register in sign-to-English interpreting". Sign Language Interpreting 16(57), 295-322.

Shlesinger, M. (1989). Simultaneous interpreting as a factor in effecting shifts in the position of texts on the oral-literate continuum. MA thesis, Tel Aviv University.

Shlesinger, M. (1995). "Stranger in paradigms: What lies ahead for simultaneous interpreting research?" Target. 7(1), 7-28.

Simon, J. (1994). An ethnographic study of sign language interpreter education. Phd dissertation, University of Arizona.

Siple, L. (1995). The use of addition in sign language transliteration. Phd dissertation, University of New York at Buffalo.

Sofinski, B. (2003). "Adverbials, constructed dialogue, and use of space, Oh My!: Nonmanual elements used in signed language transliteration". M. Metzger, S. Collins, V. Dively \& R. Shaw (eds). From Topic Boundaries to Omission: New Research on Interpretation, Studies in Interpretation, vol. 1. Washington, DC: Gallaudet University Press, 154-186.

Sofinski, B., N. Yesbeck, S. Gerhold \& M. Bach-Hansen (2001). "Features of voice-to-sign transliteration by educational interpreters". Journal of Interpretation 18, 47-68.

Steinberg, J. (2003). The use of existing video conferencing technoology to deliver video remote interpreting services for Deaf vocational rehabilitation clients. Phd dissertation, University of Arizona.

Strong, M. \& S. Rudser. (1986). “The subjective assessment of sign language interpreters”. Sign Language Studies. 15(53), 299-314.

Tate, G. \& G. Turner. (2001). "The code and the culture: Sign language interpreting - in search of the new breed's ethics". F. Harrington \& G. Turner (eds). Interpreting interpreting: Studies and reflections on sign language interpreting. Coleford, England: Douglas McLean. 53-66.

Toury, G. (1995). Descriptive translation studies and beyond. Amsterdam/Philadelphia: John Benjamins.

Turner, G. \& C. Taylor. (2001). "Working paper on access to justice for Deaf people". F. Harrington \& G. Turner (eds). Interpreting Interpreting: Studies and Reflections on Sign Langauge Interpreting. Coleford, England: Douglas McLean, 168-216.

Vermeer, H.J. (1989/2000). "Skopos and commission in translational action". L. Venuti (ed.). The Translation Studies Reader. London/New York: Routledge. 221-232.

Wadensjö, C. (1992). Interpreting as interaction: On dialogue interpreting in immigration hearings and medical encounters. Linköping University: Linköping Studies in Arts and Sciences. 
Wadensjö, C. (1998). Interpreting as interaction. London/New York: Longman.

Watson, J. (1987). "Interpreter burnout". Journal of Interpretation, 79-86.

Winston, E. (1989). "Transliteration: What's the message?" C. Lucas (ed.). The sociolinguistics of the Deaf community. San Diego: Academic Press, 147-164.

Winston, E. \& C. Monikowski. (2003). "Marking topic boundaries in signed interpretation and transliteration". M. Metzger, S. Collins, V. Dively \& R. Shaw (eds). From Topic Boundaries to Omission: New Research on Interpretation, Studies in Interpretation, vol. 1. Washington, DC: Gallaudet University Press, 187-227.

Zimmer, J. (1989). "ASL/English interpreting in an interactive setting". D. Hammond (ed.). Proceedings of the 30th Annual Conference of the American Translator's Association. Medford, NJ: Learned Information, 225-231.

\footnotetext{
${ }^{1}$ This examination is part of an ongoing study of empirical research regarding SLI that is currently being conducted within the Department of Interpretation at Gallaudet University. Special thanks are due to a number of people in gathering the studies for this project. Earl Fleetwood, Cynthia Roy, Emily Gilbert, Jeanelle Faith, Cindy Wood, Jane Rutherford. Also to Dawson Metzger-Fleetwood for his work as a research assistant and to Eric and Jill for contributing to the hours needed to code the studies.

${ }^{2}$ Some studies represented a single topic. Other studies clearly incorporated more than one topic. For instance, some studies address both interpreter effectiveness/characteristics and also the educational setting. All topics addressed are tallied, and for this reason, $100 \%$ of the studies reflect one topic (interpreter effectiveness) and yet reflect other topics as well.

${ }^{3}$ The examination of methodology incorporates both the research design (quantitative, qualitative, or mixed) and also other aspects of the study that became salient during coding of the features of the studies examined. The methodological elements that became most salient were whether or not the study was experimental or survey-based, or whether the study used naturalistic data. ${ }^{4}$ The majority of the studies examined here do not indicate the research tradition or paradigm that they reflect. For this reason, the author made this determination on the basis of Pöchhacker's description of each paradigm, in terms of the framework behind it, the methodological approaches employed within it, the kinds of data and interpreting addressed within it, and so forth.

${ }^{5}$ This paper focuses only on empirical, data-based studies, the reflective nature of this paradigm might or might not meet this requirement. Only papers that are clearly data-based were examined here. Those data-based studies that meet the description of this paradigm are categorized accordingly.

${ }^{6}$ While hearing interpreters might rarely be natively fluent in a signed language, deaf interpreters for whom a signed language is the A language, do not have sufficient access to spoken source texts. Thus, the question of working into and out of A languages is unique for signed language interpreters. For a discussion of some of the techniques used by deaf-hearing teams to allow deaf interpreters to work into their A language, see Ressler (1999) and Cerney (2005).

${ }^{7}$ Pöchhacker (2004) describes the target-text oriented approach as the most inclusive of community interpreting, rather than primarily or solely focusing on conference interpreting.
} 